\title{
Efficiency improvement of steam power plants in Kuwait
}

\author{
H. Hussain, M. Sebzali \& B. Ameer \\ Energy and Building Research Center, \\ Kuwait Institute for Scientific Research, Kuwait
}

\begin{abstract}
The main objective of this paper is to study and analyze the steam Rankine cycle for Kuwait power plant operation to come up with techniques to enhance its efficiency, hence, resulting in savings in fuel consumption as well as the reduction of harmful emissions. To achieve this objective, the Rankine cycle was modeled and simulated. The estimation of water and steam properties was also carried out. The equation-oriented approach was utilized for the process modelling as a whole with subroutines for each unit operation solved sequentially. Results showed that the steam inlet temperature had a more significant effect on the turbines' work production and the thermal efficiency than the inlet pressure. The peak efficiency also occurred at reheating to inlet pressure ratios between $10 \%$ and $20 \%$, and the thermal efficiency increased from $42.7 \%$ to about $44 \%$ when optimal feed-water heater pressures were used.
\end{abstract}

Keywords: Rankine cycle, steam turbine, energy consumption.

\section{Introduction}

The development of Kuwaiti urban life and infrastructure combined with an increase in population lead to the dependence on steam power plants to meet the demand for electricity. However, the country had problems with blackout in the past few years due to unexpected boom in expatriate, maintenance issues and rapid urbanization. After the blackout crisis of 2006, an emergency plan was put into action by the Ministry of Electricity and Water (MEW) in Kuwait to avoid a similar situation in the future. The emergency plan is based on installing a number of gas turbines in specified stations like Shuwaikh, Doha West, Sabiya and Az-Zour South. As a result of the crisis, MEW pursued a new strategy that has two 
main objectives. The first objective is to increase electricity production by building new power stations in order to overcome the rapid increase in electricity demand. The second objective is to curb peak power consumption by implementing different energy conservation methods.

It is important to note that gas turbines have low production capacities and thermal efficiencies as compared with the steam turbines. For example, the production capacity of the gas turbines installed in Kuwait ranges from 18 to 42 MW, while it ranges from 134 to $300 \mathrm{MW}$ for the steam turbines. Moreover, gas turbines require $10 \mathrm{~min}$ to start while it takes about $5 \mathrm{hrs}$ for the steam turbines to be start [1]. According, the electricity installed capacity in 2012 was $1.53 \mathrm{GW}$ while the peak load was $1.19 \mathrm{GW}$ [2]. Fig. 1 shows the total electricity installed capacity and the peak power load from 2000 to 2012 [2]. It is clear that the consumption keeps increasing and the government has to increase the production capacity continuously to avoid blackouts.

Before thinking of building a new power plant, it is important to improve the efficiency and the working conditions of the available equipment as much as possible to reduce fuel consumption and increase electricity production in existing power plants. Potential risks and maintenance problems have to be considered as well. Hence, the aim is to solve part of the problem by studying and analyzing the steam Rankine cycle, which is the working cycle used at Kuwait's steam power plants. To achieve the objectives of the study, a mathematical model was developed and simulated using data from an existing power plant in Kuwait.

The Rankine cycle is still the most widely used cycle for electric power generation. The working fluid is usually steam with the source of heat is provided by coal, oil, natural gas or nuclear fuels. To improve the efficiency and output of the Rankine cycle, variations to the basic components such as superheat, reheat and regeneration are added to the simple ideal cycle.

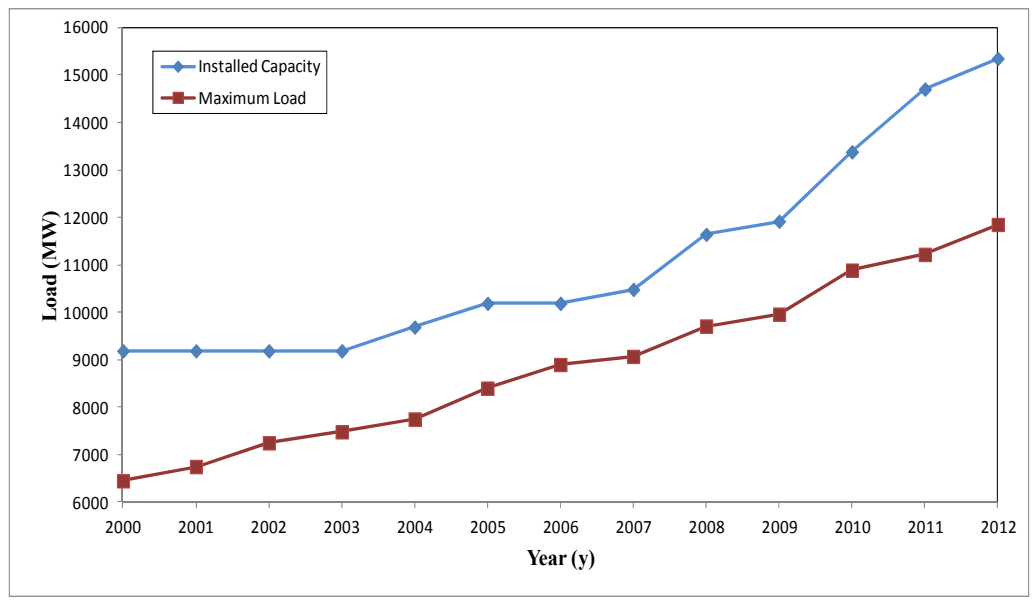

Figure 1: Kuwait electricity installed capacity vs. maximum load [1]. 


\section{Rankine cycle}

The simple Rankine cycle with superheat improves the Rankine cycle efficiency by allowing heat addition at an average temperature higher than using saturated steam only. Superheat also results in drier steam at turbine exhaust, which helps in reducing the damage to the turbine blades [3].

Superheat process is accomplished in a separate heat exchanger called a superheater located within the boiler. The combination of boiler and superheater is referred to as a steam generator $[4,5]$. The superheat temperature (i.e. turbine inlet temperature) is limited due to the endurance capacity of the blade material of the steam turbine. This temperature cannot be allowed to exceed a maximum of $560^{\circ} \mathrm{C}$ from an economic point of view $[4,6,7]$. To further increase the cycle efficiency, steam reheat is added at the exit of the high-pressure turbine. In a reheat cycle, the fed steam is partially expanded in a high-pressure turbine doing some work, and then it is fed back to the boiler where it is reheated to about its original temperature. The reheated steam then continues expanding through the lowpressure turbine to the condenser pressure. In practice, the efficiency of the reheat cycle is better than the efficiency of the superheat-steam cycle due to the increase in the average temperature at which heat is added. Another benefit of reheat is drier steam at the turbine exhaust. However, preheat presents an increased capital outlay in terms of reheater pipework.

To further enhance the thermal efficiency of the simple Rankine cycle, regenerative feed-water heating is used. The initial heating of feed-water in a simple cycle constitutes a major irreversibility in the cycle because of the large thermal potential between combustion product and the liquid water in the boiler. Regeneration solves this irreversibility problem. In regeneration, steam is bled from the turbine at selected stages to heat the liquid water before it enters the boiler via heat exchangers called feed-water heaters. Modern large steam power plants employ between five to eight feed-water heaters [3].

\subsection{Open-type feed-water heater}

In the open-type feed-water heater, the extracted steam is mixed directly with the incoming subcooled feed-water to produce saturated water at the extraction steam pressure. They also double as dearators because of the breakup of water in the mixing process liberates the noncondensable gases [3]. Referring to Fig. 2(a), the mass and energy balance for the open-type heater can be expressed as:

Mass balance: $m_{c}=m_{a}+m_{b}$

Energy balance: $m_{c} h_{c}=m_{a} h_{a}+m_{b} h_{b}$ 


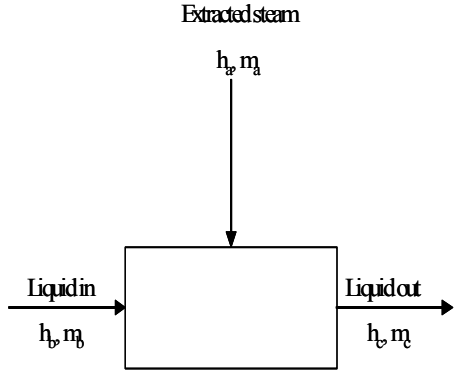

(a) Open type

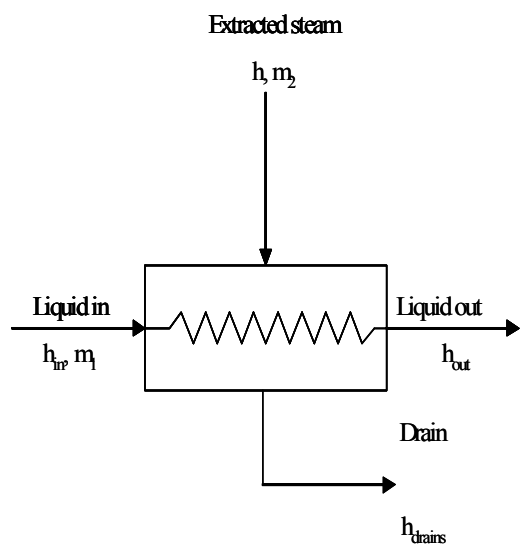

(b) Closed type

Figure 2: Mass and energy balance diagram for feed-water heaters.

\subsection{Closed-type feed-water heaters}

There are two types of closed-type heaters, drains cascaded backward and drains cascaded forward. It is a shell-and-tube heat exchanger. However, closed feedwater heaters are more complex because of the internal piping network, and therefore they require a higher capital investment [8]. The temperature of the feedwater cannot reach that of the inlet steam. A terminal temperature difference (TTD) of between $4^{\circ} \mathrm{C}$ and $6^{\circ} \mathrm{C}$ (often in the order of $5^{\circ} \mathrm{C}$ ) is practically maintained by the proper design of the heater $[3,6]$. The TTD can be defined as the difference between the saturation temperature of bled steam and the exit water temperature from heater:

$$
T T D=T_{s, \text { bled }}-T_{w, \text { exit }}
$$

From Fig. 3(b), the energy balance for the closed-type feed-water heater can be expressed as:

$$
y\left(h_{5}-h_{7}\right)=\left(h_{3}-h_{2}\right)
$$

Referring to Fig. 2(b), the above equation can be written as follows:

$$
m\left(h-h_{\text {drain }}\right)=\left(h_{\text {out }}-h_{\text {in }}\right)
$$




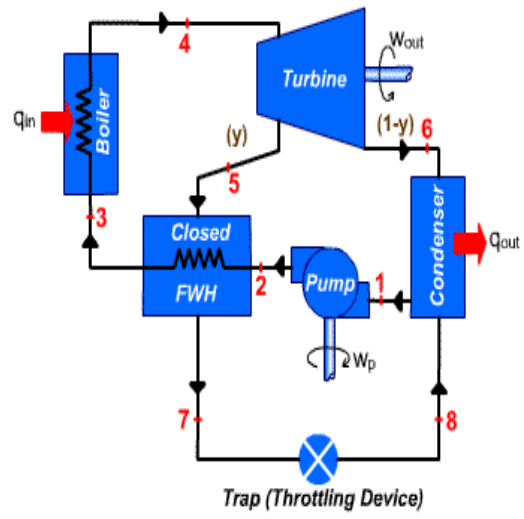

(a) Schematic diagram

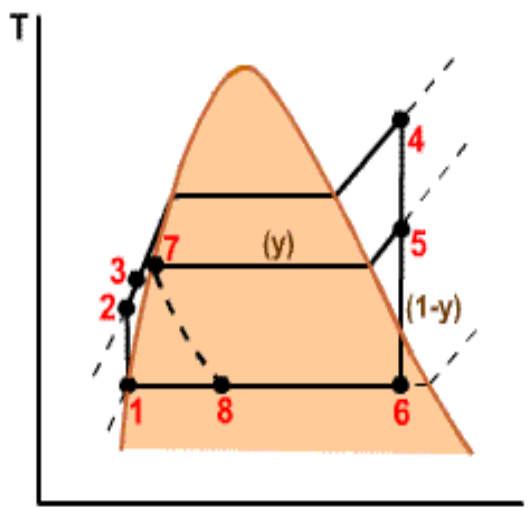

(b) T-s diagram

Figure 3: Regenerative Rankine cycle with one closed-type feed-water heater (drains cascaded backward) [7].

\section{Modeling and simulation}

Matlab software was used in this study to simulate the Doha East power plant in Kuwait. Table 1 lists operating parameters of the power plant. Figs 4 and 5 show a flow chart for the developed code and heat balance diagram of the power plant, respectively [9].

In order to simplify the calculations performed via the developed code, certain assumptions were made that do not necessarily resemble the actual operation of the power plant. Assumptions made were as follows:

- Each component is at steady state.

- All other processes are internally reversible except for the turbines and the pumps.

- $\quad$ Kinetic and potential energy effects are negligible.

- $\quad$ Pressure drop in pipes and joints is negligible.

- Steam is bled only to the feed-water heaters.

Table 1: Operating parameters of Doha East power plant.

\begin{tabular}{ll}
\hline Parameter & Value \\
\hline Output $(\mathrm{MW})$ & 300.00 \\
No. of feed-water heaters & 6 \\
Boiler mass flow rate $(\mathrm{kg} / \mathrm{s})$ & 261.04 \\
Turbine efficiency $(\%)$ & 84.32 \\
HP turbine inlet pressure (bar) & 139.00 \\
HP turbine inlet temperature $\left({ }^{\circ} \mathrm{C}\right)$ & 535.00 \\
Reheat pressure (bar) & 36.70 \\
Reheat temperature $\left({ }^{\circ} \mathrm{C}\right)$ & 535.00 \\
Condenser pressure $($ bar $)$ & 0.085 \\
\hline
\end{tabular}




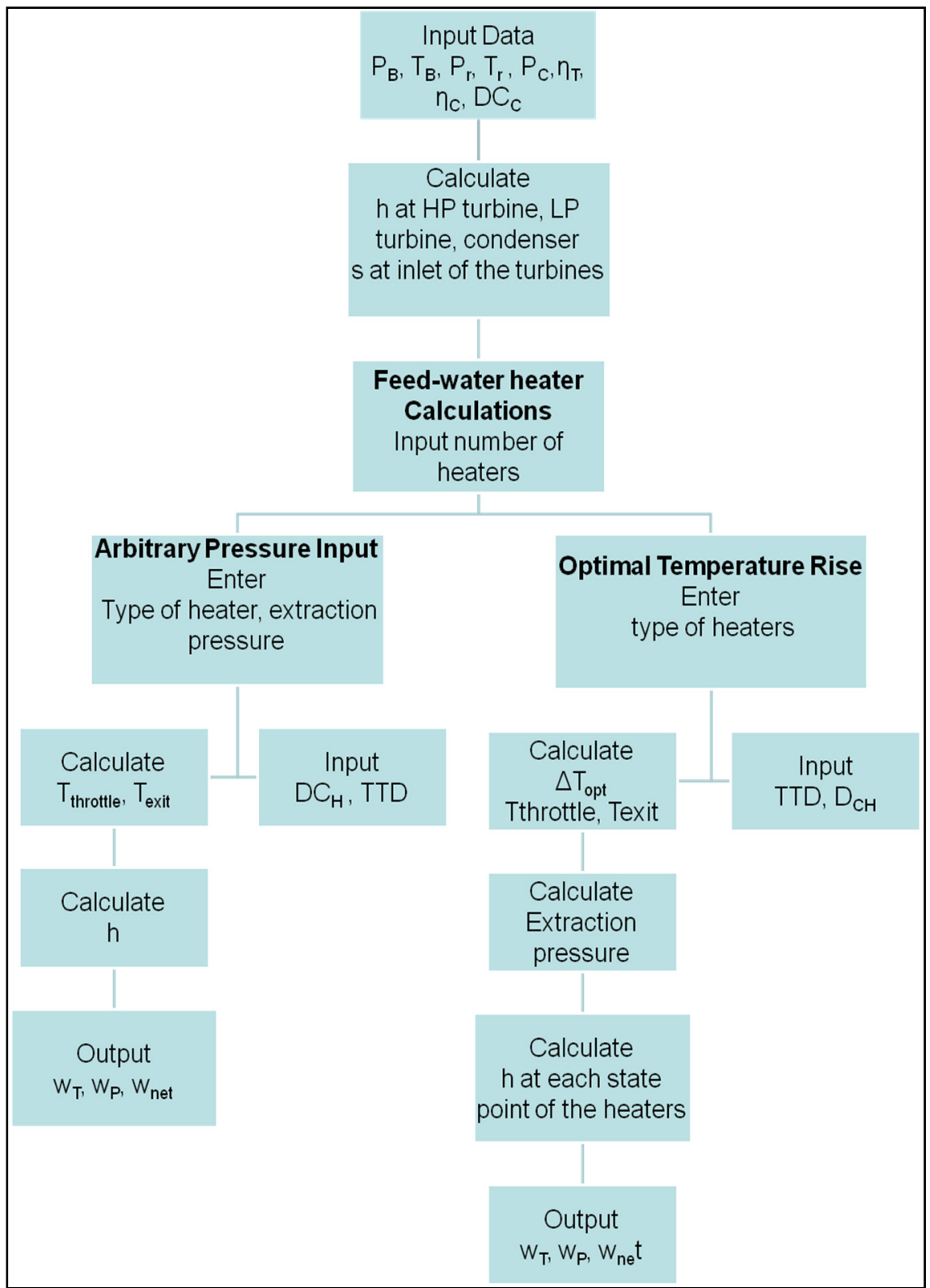

Figure 4: Flow chart for a computer program. 


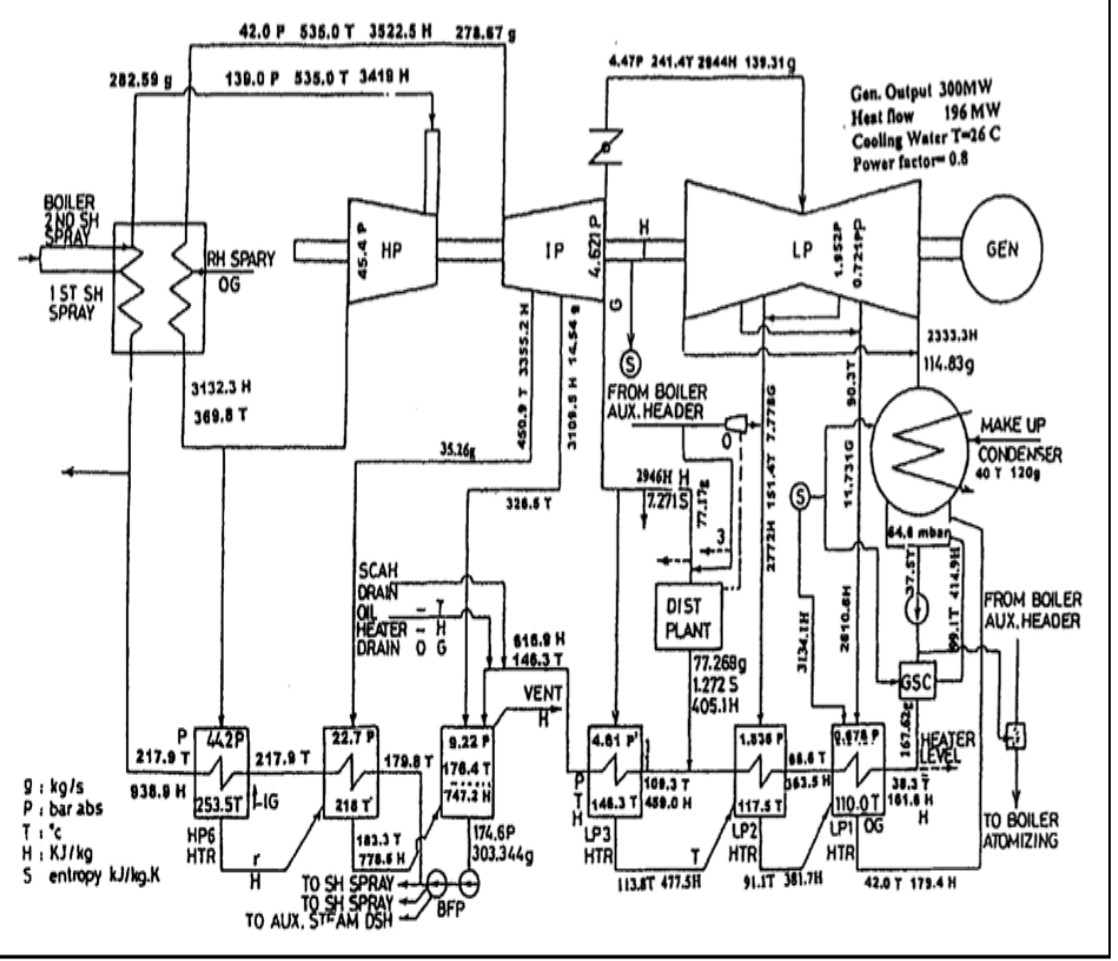

Figure 5: Heat balance diagram for a single-purpose regenerative Rankine cycle-based power plant in Kuwait [9].

\section{Results and discussion}

The plant work output was estimated when the model was simulated for optimal extraction pressures, which was lower than the output when using actual extraction pressures. However, the thermal efficiency changed from $42.7 \%$ in the case of actual pressures to $44 \%$ for optimal extraction-pressure input. The reason for the increase of the thermal efficiency is that the heat input to the boiler is lower due to the change in the extraction pressure under the optimal pressure criterion.

Fig. 6 shows the Cycle efficiency and quality as a function of reheat pressure to initial pressure ratio $(\mathrm{P} 2 / \mathrm{P} 1)$. The efficiency improved as the reheat pressure was lowered and it reached a maximum of $10 \%-20 \%$ pressure ratio [10]. It is concluded that the maximum plant efficiency occurred at a reheat pressure of about $19 \%$ of boiler pressure. At a pressure ratio of about $4 \%$, the quality of the steam entering the condenser also became above $98 \%$, which is an unfavourable situation for condenser operation. 


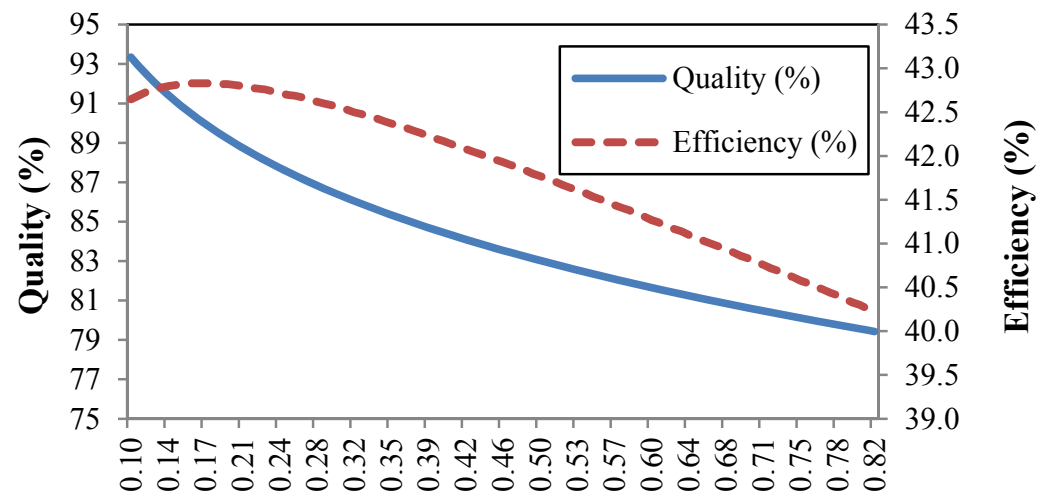

Reheat pressure/Turbine inlet pressure

Figure 6: Cycle efficiency and steam quality as a function of pressure ratio $\left(\mathrm{P}_{2} / \mathrm{P}_{1}\right)$.

The efficiency of reheat pressure to the inlet pressure ratios in the range of 0.2 to 0.28 was investigated as illustrated in Fig. 7 . An increase in the reheat pressure with respect to the inlet pressure would have a negative effect on the thermal efficiency as shown in Fig. 7 [4].

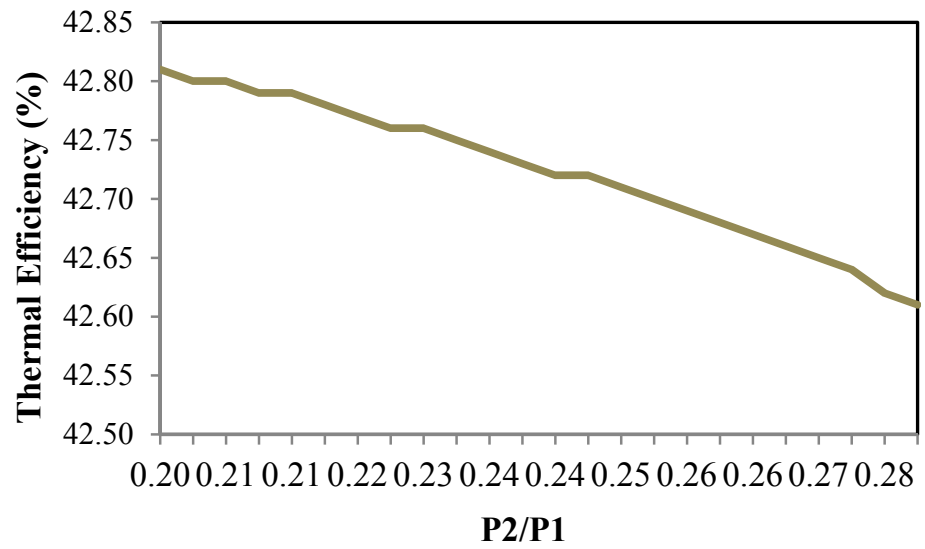

Figure 7: Thermal efficiency versus the ratio between the reheat pressure and the inlet pressure of steam into turbine.

Furthermore, Fig. 8 shows that an increase in the inlet steam pressure at constant temperature enhances the turbine work output. Additionally, an increase in the inlet temperature at the same pressure increases the turbine work output as well. However, the figure indicates that steam temperature has a more significant effect on work output compared to pressure. 


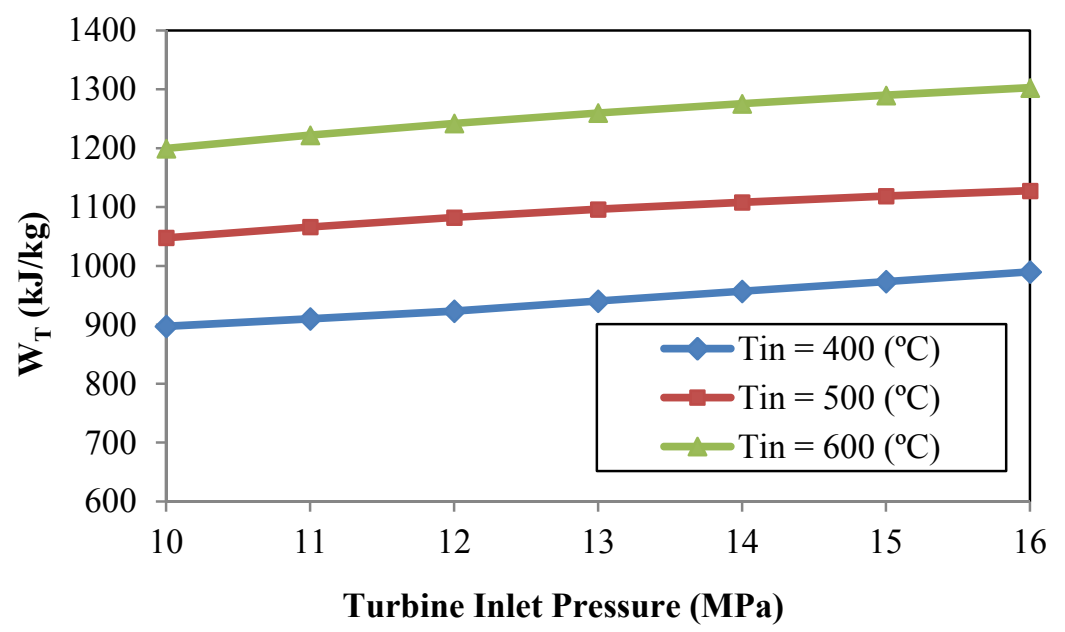

Figure 8: Turbine work with respect to inlet steam pressure at different inlet temperatures.

The efficiency of power plants was enhanced when both turbine inlet temperatures at constant pressure processes and inlet turbine steam pressures at constant temperature processes were increased as shown in Figs 9 and 10. It is worth noting that the slope of the curve in Fig. 9 is larger than the one in Fig. 10. This indicates the fact that the effect of inlet temperature on the thermal efficiency is more significant than the effect of inlet pressure. Decreasing the condenser pressure would also improve the thermal efficiency but this reduction is limited because it is a function of temperature of available cooling medium for heat rejection.

The optimum pressure for feed water heaters was calculated using the optimal temperature rise method. The inlet and outlet pressures to and from the first stage turbine were $13.9 \mathrm{MPa}$ and $3.67 \mathrm{MPa}$ respectively, while the turbine inlet temperature was $535^{\circ} \mathrm{C}$. The results of both the optimal temperature method and actual data of feed water heater pressures are shown in Table 2. It is important to note that utilizing the optimal temperature rise method had enhanced both the thermal efficiency and the heat input to the boiler. The thermal efficiency increased from about $42.7 \%$ to about $44 \%$ while the energy consumed in the boiler was reduced from $2,731 \mathrm{~kJ} / \mathrm{kg}$ to about $2,414 \mathrm{~kJ} / \mathrm{kg}$. Also, a decrease in the boiler heat reduced the fuel consumption. Additionally, the network production (pump work is subtracted from production work) decreased from about 1,164 $\mathrm{kJ} / \mathrm{kg}$ to $1,057.6 \mathrm{~kJ} / \mathrm{kg}$. 


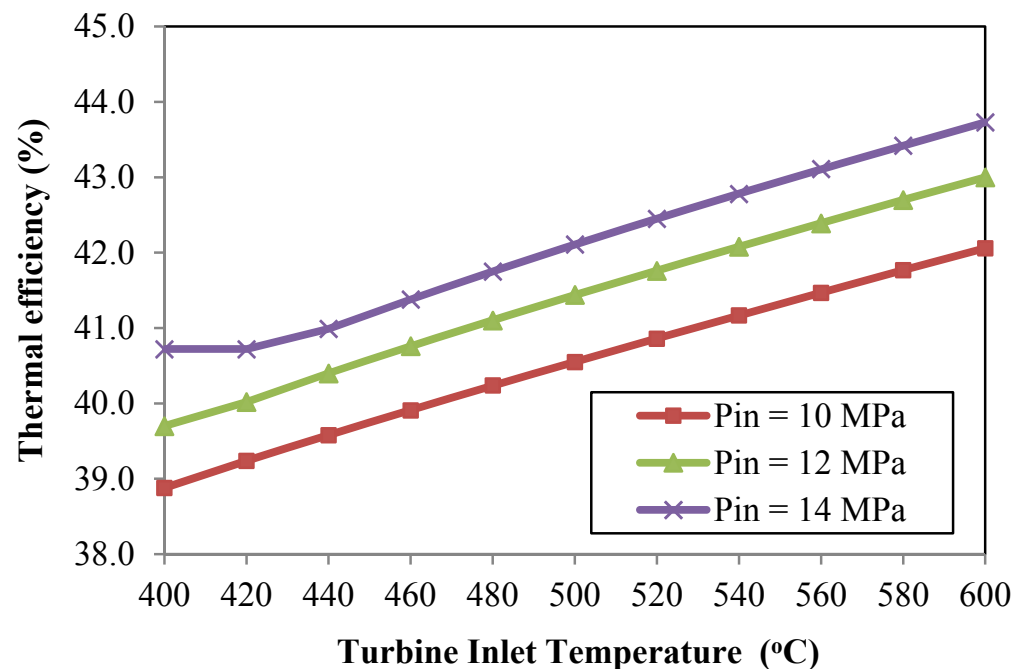

Figure 9: Thermal efficiency versus inlet steam temperature at different inlet pressures.

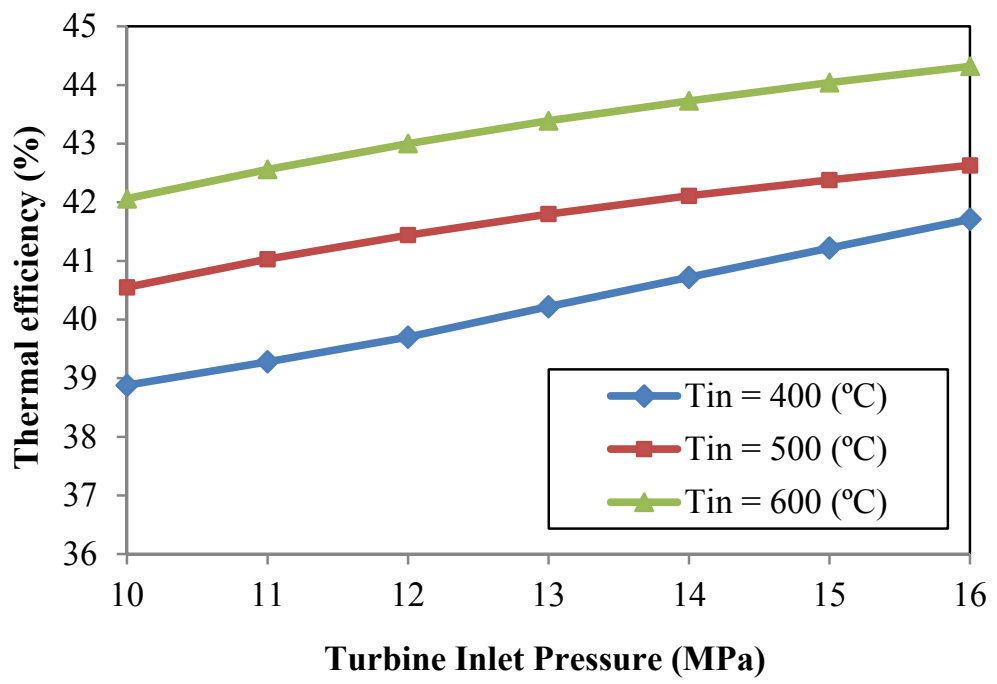

Figure 10: Thermal efficiency with respect to inlet steam pressure at different inlet temperatures. 
Table 2: Comparison of optimum temperature method and actual feed water heaters pressure.

\begin{tabular}{lccccc}
\hline Scenario & Qboiler & $\begin{array}{c}\text { Thermal } \\
\text { efficiency } \\
(\mathbf{\%})\end{array}$ & $\begin{array}{c}\text { Quality of } \\
\text { exit steam } \\
\mathbf{( \% )}\end{array}$ & $\mathbf{m}$ & $\mathbf{W}_{\text {turbine }}$ \\
\hline $\begin{array}{l}\text { Actual } \\
\text { power plant }\end{array}$ & 2,731 & 42.7 & 87.2 & 257.7 & 1,165 \\
$\begin{array}{l}\text { Optimal } \\
\text { power plant }\end{array}$ & 2,414 & 43.9 & 87.2 & 283.6 & 1,060 \\
\hline
\end{tabular}

\section{Conclusion}

The development of Kuwaiti urban life and infrastructure combined with an increase in population lead to the dependence on steam power plants to satisfy the demand for electricity. However, the country had problems with blackout in the past few years due to unexpected boom in expatriate, maintenance issues and rapid urbanization. The objective of this study was to analyze Kuwait's power plants in order to recommend any potential improvements in efficiency and reduction in fuel consumption.

Results showed that the steam inlet temperature has more significant effect on the turbine work output and the thermal efficiency of the cycle than the inlet pressure. It is also noted that an increase steam inlet temperature would increase both thermal efficiency and work production. Reheat pressure also plays a part in determining plant efficiency.

Results also showed the peak efficiency occurred at reheat to inlet pressure ratios between $10 \%$ and $20 \%$. Another way to improve the thermal efficiency of the plant is to optimize the pressures at which steam is extracted for the feed water heaters. In this study, the optimal temperature rise method was used and results showed that the efficiency increased from about $42.7 \%$ to about $44 \%$. This lead to a decrease in boiler energy consumption from $2,731 \mathrm{~kJ} / \mathrm{kg}$ to about $2,414.5 \mathrm{~kJ} / \mathrm{kg}$.

\section{References}

[1] MEW (The Kuwaiti Ministry of Electricity and Water). 2009. Electrical energy statistical year book. Publication of Ministry of Electricity and Water, Kuwait.

[2] MEW (The Kuwaiti Ministry of Electricity and Water). 2013. Electrical energy statistical year book. Publication of Ministry of Electricity and Water, Kuwait.

[3] El-Wakil, M.M. Power plant technology, McGraw-Hill: New York, 1984.

[4] Kojima, Y., Power plants for independent power producers: technical, economic and environmental assessment. MSc. Thesis. Cranfield University, Cranfield, England, 1998. 
[5] Moran, M.J. \& Shapiro, H.N., Fundamentals of engineering thermodynamics, $5^{\text {th }}$ ed. John Wiley and Sons: USA, 2004.

[6] Badr, O., Probert, D. \& O'Callaghan, P. Rankine cycles for steam powerplants. Applied Energy 36(3), pp. 191-231, 1990.

[7] University of Oklahoma. On-line lectures on Rankine cycles, 2004. http://coecs.ou.edu/Feng.Chyuan.Lai/thermoweb. (Accessed $20^{\text {th }}$ June 2004).

[8] Cengel, Y. A. \& Boles, M. A., Thermodynamics: an engineering approach. $2^{\text {nd }}$ ed., McGraw-Hill Inc.: USA, 1994.

[9] Darwish, M. A. 2001. Electric power and desalted water production in Kuwait. Desalination 138: 183-190.

[10] Habib, M. A., Said S. A. M. \& Al-Zaharna, I. Optimization of reheat pressures in thermal power plants. Energy 20(6), pp. 555-565, 1995. 